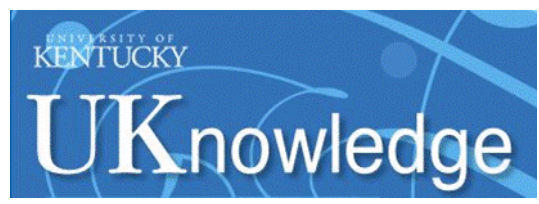

University of Kentucky

UKnowledge

\title{
Terminate Lung Cancer (TLC) Study-A Mixed-Methods Population Approach to Increase Lung Cancer Screening Awareness and Low-Dose Computed Tomography in Eastern Kentucky
}

Roberto Cardarelli

University of Kentucky, roberto.cardarelli@uky.edu

David Reese

Appalachian Osteopathic Postgraduate Training Institute Consortium

Karen L. Roper

University of Kentucky, karen.roper@uky.edu

Kathryn Cardarelli

University of Kentucky, kathryn.cardarelli@uky.edu

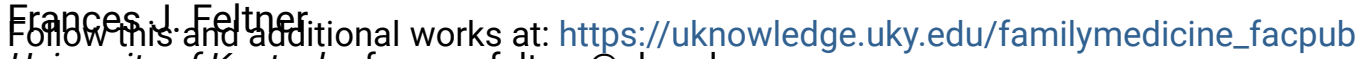
I Iniversity of Kentucky, frances.feltner@uky.edu

Part of the Epidemiology Commons, and the Oncology Commons

Right click to open a feedback form in a new tab to let us know how this document benefits you. See next page for additional authors

\section{Repository Citation}

Cardarelli, Roberto; Reese, David; Roper, Karen L.; Cardarelli, Kathryn; Feltner, Frances J.; Studts, Jamie L.; Knight, Jennifer R.; Armstrong, Debra; Weaver, Anthony D.; and Shaffer, Dana, "Terminate Lung Cancer (TLC) Study-A Mixed-Methods Population Approach to Increase Lung Cancer Screening Awareness and Low-Dose Computed Tomography in Eastern Kentucky" (2017). Family and Community Medicine Faculty Publications. 4.

https://uknowledge.uky.edu/familymedicine_facpub/4

This Article is brought to you for free and open access by the Family and Community Medicine at UKnowledge. It has been accepted for inclusion in Family and Community Medicine Faculty Publications by an authorized administrator of UKnowledge. For more information, please contact UKnowledge@lsv.uky.edu. 


\section{Terminate Lung Cancer (TLC) Study-A Mixed-Methods Population Approach to Increase Lung Cancer Screening Awareness and Low-Dose Computed \\ Tomography in Eastern Kentucky}

Digital Object Identifier (DOI)

https://doi.org/10.1016/j.canep.2016.11.003

Notes/Citation Information

Published in Cancer Epidemiology, v. 46, p. 1-8.

(C) 2016 Elsevier Ltd. All rights reserved.

This manuscript version is made available under the CC-BY-NC-ND 4.0 license http://creativecommons.org/licenses/by-nc-nd/4.0/

\section{Authors}

Roberto Cardarelli, David Reese, Karen L. Roper, Kathryn Cardarelli, Frances J. Feltner, Jamie L. Studts, Jennifer R. Knight, Debra Armstrong, Anthony D. Weaver, and Dana Shaffer 
(C) 2016 Elsevier Ltd. All rights reserved.

This manuscript version is made available under the CC-BY-NC-ND 4.0 license

http://creativecommons.org/licenses/by-nc-

nd/4.0/ 
Terminate Lung Cancer (TLC) Study - A mixed-methods population approach to increase lung cancer screening awareness and low-dose computed tomography in Eastern Kentucky

Roberto Cardarelli ${ }^{\mathrm{a}}$

David Reese ${ }^{\mathrm{b}}$

Karen L. Roper ${ }^{\mathrm{a}}$

Kathryn Cardarelli ${ }^{\mathrm{c}}$

Frances J. Feltner ${ }^{\mathrm{d}}$

Jamie L. Studts

Jennifer R. Knight ${ }^{f}$

Debra Armstrong ${ }^{g}$

Anthony Weaver ${ }^{\mathrm{h}}$

Dana Shaffer ${ }^{\mathrm{i}}$

Affiliations:

${ }^{a}$ University of Kentucky College of Medicine, Department of Family \& Community Medicine / Division of Community Medicine, 2195 Harrodsburg Road, Lexington, KY, 40504-3504 USA

${ }^{\mathrm{b}}$ Appalachian Osteopathic Postgraduate Training Institute Consortium, POSTAL Pikeville, KY, USA

'University of Kentucky College of Public Health / Department of Health, Behavior, \& Society, POSTAL Lexington, KY, USA

${ }^{\mathrm{d}}$ University of Kentucky College of Medicine, Center of Excellence in Rural Health \& Kentucky Homeplace, POSTAL Hazard, KY, USA 
eUniversity of Kentucky College of Medicine, Department of Behavioral Science, POSTAL

Lexington, KY, USA

${ }^{\text {f } U n i v e r s i t y ~ o f ~ K e n t u c k y ~ C o l l e g e ~ o f ~ P u b l i c ~ H e a l t h ~ / ~ D e p a r t m e n t ~ o f ~ H e a l t h ~ M a n a g e m e n t ~ a n d ~}$

Policy, POSTAL Lexington, KY, USA

'The Kentucky Cancer Program, POSTAL Lexington, KY, USA

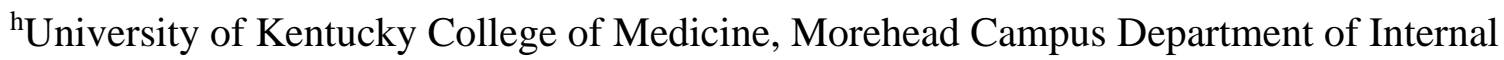

Medicine, POSTAL Morehead, KY, USA

${ }^{\text {i}}$ University of Pikeville, Kentucky College of Osteopathic Medicine; Appalachian Osteopathic

Postgraduate Training Consortium, POSTAL Pikeville, KY, USA

Corresponding Author: Karen L. Roper, PhD, University of Kentucky College of Medicine, Department of Family \& Community Medicine, 2195 Harrodsburg Road, Lexington, KY 405043504; Email: karen.roper@uky.edu; Phone: 859-323-3711; Fax: 859-323-6661

Financial Disclosures: None.

Supplementary Material:

Tables: 2

Figures: 3

Key words: Lung cancer, Screening, Prevention, Appalachia 


\begin{abstract}
For low dose CT lung cancer screening to be effective in curbing disease mortality, efforts are needed to overcome barriers to awareness and facilitate uptake of the current evidence-based screening guidelines. A sequential mixed-methods approach was employed to design a screening campaign utilizing messages developed from community focus groups, followed by implementation of the outreach campaign intervention in two high-risk Kentucky regions. This study reports on rates of awareness and screening in intervention regions, as compared to a control region.
\end{abstract}




\section{Introduction}

Lung cancer remains the leading cause of cancer death in the United States, ${ }^{1}$ accounting for about 1 in 4 cancer deaths. ${ }^{2}$ Early detection of the disease is notoriously poor, with only $16 \%$ of lung cancers diagnosed at a localized stage. The 5-year survival rate is $55 \%$ with early detection; however, this rate is cut in half $(27 \%)$ if detected after regional spread. ${ }^{2}$ The potential for change in these statistics will be of special interest in the coming years, given the national coverage decision on Feb. 5, 2015, by the Centers for Medicare and Medicaid Services (CMS) for low dose computed tomography (LDCT) lung cancer screening for eligible Medicare beneficiaries. ${ }^{3}$ The CMS decision followed evidence from the National Lung Screening trial (NLST) that LDCT reduced lung cancer mortality by $20 \%$ compared to standard chest x-ray among adults with at least a 30 pack-year smoking history who were current smokers or had quit within 15 years. ${ }^{4}$ Review of the few existing studies on cost analytics, calculated as savings from a shift toward earlier stages at diagnosis relative to increased Medicare expenditures for screenings, also describe favorable results. ${ }^{5}$

Along with interventions to curb high rates of smoking, few states stand to benefit more from LDCT screening efforts than Kentucky. Compared to national averages for age-adjusted lung cancer incidence and mortality (63.7 and 47.2 per 100,000, respectively), Kentucky’s rates of 97.5 and 70.9 per 100,000 , respectively, are the highest in the nation. ${ }^{6}$ The impact of the recommendation itself, however, is likely to be minimal unless efforts are made to overcome implementation delays and barriers to awareness and uptake of evidence-based screening guidelines. ${ }^{7}$ Early studies on implementation of LDCT screening show that patients are not aware of the recommendation ${ }^{8}$ and have limited knowledge of what a screening might entail ${ }^{9}$ 
primary care providers also have shown limited understanding of the guidelines or the evidence for LDCT effectiveness. ${ }^{10,11}$

One of the CMS requirements when ordering a chest LDCT for lung cancer screening is documentation that a shared decision-making process was conducted and recorded in the medical record. ${ }^{3}$ This process is important, given that a primary concern for roll-out of LDCT screening is the risk associated with a false-positive result, ${ }^{12,13}$ for which the implications (e.g., follow-up testing with the potential for more invasive biopsies and additional radiation) need to be properly identified and discussed with the patient. The requirement for shared decision-making is meant to assure that the potential risks, benefits, limitations, and uncertainties associated with LDCT screening are conveyed to the patient and that the patient has an opportunity to ask questions before a LDCT is ordered. Effectiveness of these sessions may be limited, however, given concern among providers that a lack of patient knowledge about LDCT presents a major barrier to LDCT screening. ${ }^{10}$ There is a clear need to address this knowledge gap as part of the larger effort to facilitate mutual respect and effective communication processes that are known to enhance the shared decision making process. ${ }^{14}$

Our team assessed whether a population approach to increasing awareness of the new guidelines might be effective in addressing the expectedly slow uptake of the screening initiative. To this end, we developed a community awareness campaign about the importance of lung cancer screening that would be especially sensitive to the unique cultural attitudes and perspectives in the high-need area of Eastern Kentucky. Our community-engaged approach utilized focus groups of local individuals who met criteria to be considered high-risk for lung cancer. Focus groups were gathered to elicit their opinions about lung cancer, lung cancer screening, and perceived salient and trusted messages about screening. Here we report on the 
effectiveness of the resulting campaign, known as the Terminate Lung Cancer (TLC) program, based on community awareness of screening and rates of LDCT orders across two targeted Eastern Kentucky regions. Prior research describes development of our campaign materials and highlights our community-engaged approach as informed by our focus group efforts. ${ }^{9} \mathrm{We}$ hypothesized that if our TLC program had met its goal of motivating patients to approach their health providers about their options for LDCT, there would be an increase in order rates for LDCT as compared to a control region where the campaign had not been implemented.

\section{Methods}

2.1. Targeted population regions.

We targeted three Eastern Kentucky regions located in and around the counties with the residing cities of Morehead, Hazard, and Pikeville, KY (Figure 1). Each of these areas is burdened with significant health disparities, and is characterized by significant behavioral, educational, and economic disparities (see Table 1).

\subsection{Mixed methods approach.}

A sequential mixed-methods approach was implemented with focus group sessions conducted in October 2014, followed by implementation of the community outreach intervention in two intervention regions (Morehead and Hazard regions). The Pikeville region did not receive the marketing intervention and served as a control region for assessment of LDCT rates. All study procedures were approved by the University of Kentucky Institutional Review Board.

\subsubsection{Focus groups and focus group findings.}

Two focus groups were conducted in each region (six in total) in October 2014. Community health workers (CHWs) from Kentucky Homeplace (a health service organization 
with a long collaborative history of supporting high-risk populations) recruited individuals from their local communities using established client files. Identified were men and women 55-77 years of age with at least 30 pack-years of smoking: either former smokers (quit in last 15 years), or current smokers. These criteria match those for lung cancer screening. A total of fifty-four individuals (61.1\% female; >55 pack year history) participated.

All sessions were recorded and transcribed for independent content analysis, with results described in a previous publication. ${ }^{9}$ Among the findings from these deliberative sessions was a list of themes that were identified for their potential effectiveness; these included messages about survivorship, family, and prolonged life. There was strong consensus among participants of the importance of testimony, such as seeing a picture of someone who had survived lung cancer after screening. With regard to the various venues and channels that might be used to disseminate information about lung cancer screening, this largely older and rural audience showed heavy reliance on information gained from their health providers, as well as family and friends. Recommendations also included: Flyers or information in doctor offices/waiting rooms and during annual exams; making LDCT screening information available in internet searches and in health websites; placing flyers in grocery stores and by direct mail; and traditional advertising using television, newspaper, and radio advertisements.

\subsubsection{Development of lung cancer screening campaign: Campaign elements.}

The media, venues, and methods of the campaign were informed by the outcomes of the focus group data described above. We developed messaging and images for postcard mailings and newspaper ads that included a TLC website address (See Figure 2). The TLC campaign did not include any television advertisements due to cost limitations. As described in our previous publication $^{9}$, two members from each focus group were asked to serve on an advisory board that 
participated in the development of the campaign elements, including final approval of all venues and materials used. Their function was to provide input and direction to ensure that perspectives of the targeted population, as derived from the focus groups in which they participated, were fully vetted and reflected in the messages and outcomes produced. The final materials (see Figure 2) were selected to portray the common message of hope and survival, as this was an overriding theme discussed during the focus groups.

\subsubsection{Campaign dissemination (intervention).}

With importance given to information provided by a family doctor or specialty provider, we mailed 54,600 postcards equally within the intervention regions to 64 locations that included primary care, community health providers, county public health departments, and agricultural extension offices (AEOs). The University of Kentucky was founded as a land grant institution and has an enduring history of working with AEOs to engage rural populations for health education. A national framework developed by the Extension Committee on Organization \& Policy of the Association of Public and Land-grant Universities has linked drivers utilizing AEOs and community-based health resources. ${ }^{15}$

Along with the postcards, we enclosed information specific to providers on the LDCT guidelines, and a crosswalk comparison of the CMS coverage and the United States Preventive Services Task Force recommendations. We developed a website (www.terminatelungcancer.org) with links and resources for community members and providers, and sent a second letter to the same providers marketing the website. We held a physician roundtable event to provide an overview of our project and the LDCT screening guidelines in the Morehead region, which was attended by 26 physicians. A Hazard region roundtable was unfortunately canceled due to an insufficient number of registered participants. 
For broader community coverage, we purchased ads using the same design as the postcards that ran every 2 weeks in 17 community newspapers $(9$ in the Morehead region and 8 in the Hazard region). For radio coverage, we ran ads on the local public radio station in the Morehead region twice daily for 6-months. Likewise in the Hazard region, we worked with 2 local radio stations to run our spot one or more times per day. The radio ads message is shown in Figure 2.

2.3. Outcome measures

2.3.1. Exposure and Behaviors Survey.

In order to assess reach of the campaign and community access to our dissemination efforts, we analyzed results from a telephone survey that was administered by three CHWs from each region. Call lists were generated from Kentucky Homeplace using their established client files to include members meeting the screening criteria described above, excluding any individuals who had participated in any of the prior six focus groups sessions. In their telephone call, respondents were asked if they had seen or heard any advertising, or other exposure, concerning lung cancer screening. If a respondent answered yes, they were asked where the ad was seen and/or heard, and if the exposure influenced them toward any specific considerations or to take action toward screening or smoking cessation.

\subsubsection{LDCT uptake.}

Three hospital systems (each non-affiliated with each other or with an academic center) partnered with the study. Each hospital is located in one of the 3 study regions, and each serves as the largest system with LDCT capacity for their respective region. To assess effectiveness of the campaign, we analyzed the monthly totals of chest LDCTs (CPT 71250) performed for any 
ICD-9 code and those for an associated ICD code V76.0 (Special screening for malignant neoplasms of the respiratory organs) or V15.82 (Personal history to tobacco use, current/former ages 55-80 years) for the prior 12-months from each regional imaging center. These data were requested at baseline (end of 2014) and, again, post-intervention (end of 2015).

To monitor for external marketing activity by regional systems, specifically by hospital centers that offer LDCT, our team called and sent emails attempting to reach each hospital's director of marketing, radiology or medical imaging center, and/or supervisor for oncology services. Feedback from this assessment was used to qualitatively interpret comparative analyses of campaign effectiveness.

\subsection{Statistical approach.}

Survey results were assessed using descriptive and bivariate analyses. Counts and frequencies were calculated and chi-square analysis was performed to assess for statistical differences between the three studied regions. Statistical significance was achieved based on a $p$ value $<0.05$ using SPSS version 21.0 software.

\subsubsection{LDCT-Statistical process control.}

We used statistical process control with our primary process measure of LDCTs for each region (calculated as number of LDCTs performed per population 100,000) displayed on control (c-) charts. This methodology assesses whether a process is stable (with variation only coming from sources that would be usual or common to the process), and we used established rules for differentiating special versus common cause variation for each c-chart. ${ }^{16-18}$ We plotted TLC campaign elements on the c-charts to assess for any temporal trends that may have arisen. Upper and lower control limits (UCL and LCL, respectively) were used to determine if special cause 
variation (points on the timeline that exceed estimates of expected variability) achieved statistical significance. UCL and LCL for c-control charts are based on count data that are assumed to follow a Poisson distribution and based on the central limit theorem. ${ }^{19}$ Standard deviations are calculated as the square root of the mean central line defined as the sum of events (i.e., LDCTs) divided by the number of subgroups (i.e., number of time points). The upper and lower control limits are then calculated as the mean central line $+/-3$ multiplied by the square root of the mean central line.

\section{Results}

\subsection{Study population regions}

While the Eastern Kentucky region is very homogenous, the region drastically differs in several measures when compared to non-Appalachia Kentucky and the rest of the US. Low education and income levels, as presented in Table 1, are lower in the study regions when compared to Kentucky and the US. In addition, smoking rates are almost doubled when compared to the US and approximately 5\% higher than the state average. Similar disproportionate patterns are observed for premature death and cancer death rates.

\subsection{Exposure and Behaviors Survey results.}

CHWs attempted to reach at least 50 screening-eligible individuals in each of the three regions. A total of 145 surveys were completed in all regions combined. Seventy-three (50.3\%) answered "Yes" to the question of whether they had "seen or heard ads, messages, or postcards about lung cancer screening in doctor offices, local newspapers, or on the radio in the last 4-6 months." When the 73 individuals were asked if this exposure had led to any consideration and/or action, a total of 61 individuals $(83.6 \%)$ reported a positive response for at least one 
consideration or action taken, with a total of 100 considerations or behaviors reported. Results of this survey, including reports of exposure to the different campaign elements (described next), are shown in Table 2.

Comparison of individuals reporting that they had seen or heard about lung cancer screening in the last 4-6 months did not reveal any significant difference in overall exposure across the three regions $(p=0.13)$. There were significant differences in the type of activity to which regions were exposed. Our two intervention regions both reported high rates of radio ad exposure compared to the Pikeville (Control) region $(p=0.02)$. The Morehead region had the highest percentage reporting exposure to postcards in doctor offices and newspaper ads $(p=0.01)$, with lower rates in the Hazard and Pikeville regions. A large percentage of respondents in the Pikeville (Control) region stated that they had seen television ads about lung cancer screening (not part of our campaign), which was significantly more than was found amongst those surveyed in the intervention regions $(p<.001)$.

\subsection{LDCT results.}

As shown on the c-charts for each region, there was a significant uptake (exceeding the upper control limit) of LDCTs in the two intervention regions (Figure 3a), while no statistical significance was achieved in the Control region (Figure 3b). Moreover, the increasing trend in uptake of LDCTs was noted to occur after incremental elements of the TLC campaign were implemented. The Morehead region more than doubled the number of LDCTs per 100,000 population from the beginning of 2015 and the Hazard region went from 0 to over 10 LDCTs per month per 100,000 population. The Pikeville (Control) region began with a baseline of 0 to 4 LDCTs per month per 100,000 population, and failed to reach the upper control limit, peaking at little over 6 LDCTs per month per 100,000 population. 


\section{Discussion}

4.1. Summary of results in context of literature.

Translating recommendations and guidelines into practice is a lengthy process, taking an estimated 17 years to proceed from initial discovery to clinical implementation. ${ }^{20}$ The U.S. health care system heavily relies on published reports and continuing education to disseminate new guidelines, with the expectation that implementation will occur shortly thereafter - a passive practice that has not proven effective. ${ }^{21,22}$ Our study assesses the impact of directly disseminating knowledge and information to communities in Eastern Kentucky. The messaging and awareness campaign sought to encourage high-risk individuals to speak with their health care provider about whether lung cancer screening was appropriate for them. Through our population-level comparative analyses, we demonstrated significant uptake of LDCTs in intervention regions compared to a control region. This study provides preliminary evidence that implementing population approaches may be a viable method to disseminate new guidelines. Our study adds to existing literature on best practices and effectiveness of educational outreach (e.g., Greenhalgh et al. ${ }^{23}$ and the $A H R Q^{24}$ ) among strategies that facilitate the knowledge translation process; ${ }^{25}$ and perhaps more importantly, addresses the recognized academic-community divide that often limits the reach and/or meaningfulness of the education provided to the community. ${ }^{26}$

As noted in the findings from our survey of exposure and behavior, the lung cancer screening campaign inadvertently triggered thought processes concerning smoking cessation. This was a welcome unintended consequence of the campaign, and indicates that the participating population was aware that smoking is the primary risk factor for lung cancer. The finding also adds to the growing evidence base that smoking cessation interventions can be successfully implemented in screening settings. ${ }^{27,28}$ Evidence that patients associate smoking 
behaviors and the need for screening is important, given that CMS lung cancer screening guidelines require counseling on the importance of smoking cessation as part of the national coverage requirement, in addition to the shared decision making activities described earlier.

\subsection{Limitations.}

The location of our study may limit the generalizability of the results to other regions in the United States. First, our demographic is predominantly white, with approximately $85 \%$ of Kentucky residents in 2015 classified as White alone, not Hispanic or Latino (compared to $61.6 \%$ of the US population). The white demographic is even more prevalent in our study regions of Clay (92.7\%), Pike (97.1\%) and Rowan (94.5\%) counties. ${ }^{29}$ Second, advertising efforts in this region were specifically targeted to the unique population of individuals that live in rural Appalachian regions. Persons in these areas may not be reflective of other populations in terms of educational or other socio-demographic characteristics (see again, Table 1) or in terms of their access to campaign features that may be effective in other areas. For example, while our focus groups did communicate interest in obtaining health information from the internet, we did not anticipate this would be a strong driver for our campaign given that state statistics show that $23 \%$ of rural (and only $1.5 \%$ of urban) Kentuckians were without any internet access at the time of this study. ${ }^{30}$ Thus, while our TLC website may serve as a model for the type of messaging that may be effective within that community, web and social media marketing could be of greater utility within more "connected" population centers than was explored here.

Another challenge in examining the effects of our advertising campaign on LDCT uptake related to the diffusion effects of the intervention to other regions, and evidence that we obtained for competing marketing that cannot be controlled. Methodologically, it is impossible to establish causality using our design. It is always difficult to establish a true control community 
for purposes of comparison, because one cannot assume that the community involved will remain static or uninfluenced by other campaigns or factors occurring in the experimental communities. ${ }^{31}$ Respondents to our campaign exposure assessment within our Pikeville (Control) region stated that they had exposure to television ads about lung cancer screening; and in our effort to contact marketing agents we received information from one hospital system in the region that it had undergone an extensive lung cancer screening campaign. Indeed, given the level of exposure to LDCT marketing in the region that served as our Control, the greater effectiveness on obtained LDCT orders in our intervention regions speaks to the success of our campaign. It should be noted that while we were unable to obtain information about the content of the external ads, recent research shows aggressive appeals can make smokers feel stigmatized and engender distrust. ${ }^{32}$ We suggest that our campaign, by using images and captions that express hope and survivorship and encouraged consultation with a physician or other clinician, offered a positive emotional message that was more trusted and stimulated more desired activity. Measuring campaign dissemination effectiveness based on rates of LDCT orders presented additional challenges since the outcome measure depended on operational readiness to facilitate the change. Uptake of LDCT screening guidelines is likely to be affected by a host of systematic and administrative hurdles that delay order rates, and thus our reported rates may not adequately reflect the rate of screening that could be expected in later campaigns. In fact, in the assessment of the marketing efforts outside of our campaign, several hospital administrators outside of our LDCT centers commented that they haven't gotten the reimbursement "figured out yet" to begin screening. Nonetheless, our three hospital system partners were performing LDCT screenings, but differed in their maturity in operating and sustaining a lung cancer screening 
program. Another limitation is that we did not capture LDCTs that may have resulted from our campaign that were performed outside of our three partnering hospital systems.

\section{Conclusion}

Lung cancer accounts for approximately $20 \%$ of the total cost of cancer care to Medicare, with aggregate costs of $\$ 4.2$ billion spent over a five-year span of care ( $\$ 1-2$ billion more than the cost of colorectal or prostate cancer). ${ }^{33}$ Alerting to the need for early detection, these costs are known to increase for patients with more advanced disease at the time of initial diagnosis. Unfortunately, those costs are often incurred by those who can least afford it, since late-stage diagnosis has been associated with lower socioeconomic status. ${ }^{34,35}$ Our goal was to increase lung cancer screening rates by addressing the knowledge barrier about LDCT screening processes, benefits, and risks in a community population known for significant health disparities and health-risk behaviors. While we found increases in each of our target regions, further research is needed to ascertain the true impact of population-level interventions in the dissemination and implementation process of new evidence-based screening guidelines. 
Acknowledgements: The authors wish to thank TLC community focus group members, especially those that served in our Community Advisory Board for their work in developing TLC materials. Collaboration from across several agencies is recognized by our authorship team and we are grateful to their host institutions for supporting this partnership. We also want to thank our community hospital partners including St. Claire Regional Medical Center in Morehead KY, Appalachia Regional Hospital in Hazard KY, and Pikeville Medical Center in Pikeville KY.

Funding: This work was supported by the Center for Clinical and Translational Science: Appalachian Translational Research Network Grants Program, with support from National Institutes of Health [Center for Research Resources \& National Center for Advancing Translational Sciences]. Additional funding was provided by the University of Kentucky Markey Cancer Center.

Conflicts of Interest: none 
References

1. Siegel R, Naishadham D, Jemal A. Cancer statistics, 2013. CA Cancer J. Clin. 2013;63(1):11-30.

2. American Cancer Society. Cancer Facts \& Figures 2016. Atlanta, GA: 2016.

3. Centers for Medicare \& Medicaid Services. Decision Memo for Screening for Lung Cancer with Low Dose Computed Tomography (LDCT) (CAG-00439N). Feb 5, 2015.

4. National Lung Screening Trial Research Team, Aberle DR, Adams AM, et al. Reduced lung-cancer mortality with low-dose computed tomographic screening. N. Engl. J. Med. 2011;365(5):395-409.

5. Pyenson B, Dieguez G. 2016 reflections on the favorable cost-benefit of lung cancer screening. Ann TranslMed. 2016;4(8):155.

6. National Cancer Institute and the Centers for Disease Control. State Cancer Profiles. Created by statecancerprofiles.cancer.gov on 07/01/2016 12:31 pm.; http://statecancerprofiles.cancer.gov/quick-profiles/index.php?statename=kentucky\#t=0.

7. Grimshaw JM, Thomas RE, MacLennan G, et al. Effectiveness and efficiency of guideline dissemination and implementation strategies. Health Technol. Assess. 2004;8(6):iii-iv, 1-72.

8. Retrouvey M, Patel Z, Shaves S. US Preventive Services Task Force CT Lung Cancer Screening Recommendations: Community Awareness and Perceptions. J Am Coll Radiol.: JACR. 2016;13(2 Suppl):R35-37.

9. Cardarelli R, Roper KL, Cardarelli K, et al. Identifying Community Perspectives for a Lung Cancer Screening Awareness Campaign in Appalachia Kentucky: The Terminate Lung Cancer (TLC) Study. J. Cancer Educ. 2015:1-10.

10. Lewis JA, Petty WJ, Tooze JA, et al. Low-Dose CT Lung Cancer Screening Practices and Attitudes among Primary Care Providers at an Academic Medical Center. Cancer Epidemiol Biomarkers Prev. 2015; 24:664-670.

11. Ersek JL, Eberth JM, McDonnell KK, et al. Knowledge of, attitudes toward, and use of low-dose computed tomography for lung cancer screening among family physicians. Cancer. 2016;122(15):2324-2331.

12. Bach PB, Mirkin JN, Oliver TK, et al. Benefits and harms of ct screening for lung cancer: A systematic review. JAMA. 2012;307(22):2418-2429.

13. Tanner NT, Silvestri GA. Lung cancer screening with low-dose CT: benefits and potential risks. Evid. Based Med. 2013;18(3):108-109.

14. Kredo T, Bernhardsson S, Machingaidze S, et al. Guide to clinical practice guidelines: the current state of play. Int. J. Qual. Health Care. 2016;28(1):122-128.

15. Association of Public and Land-grant Universities, Committees on Organization and Policy (COPs). Cooperative Extension's National Framework for Health and Wellness. March 2014. Available at: http://www.aplu.org/members/commissions/foodenvironment-and-renewable-resources/CFERR_Library/national-framework-for-healthand-wellness/file?id=5134.

16. Provost LP, Murray SK. The health care data guide: learning from data for improvement, 1st ed. San Francisco, CA: Wiley; 2011.

17. Carey RG. Improving Healthcare with Control Charts: Basic and Advanced SPC Methods and Case Studies. Milwaukee, WI: Amer Society for Quality Press; 2003.

18. Benneyan J, Lloyd R, Plsek P. Statistical process control as a tool for research and healthcare improvement. Qual Saf Health Care. 2003;12(6):458-464. 
19. Carey RG, Lloyd RC. Measuring Quality Improvement in Healthcare: A Guide to Statistical Process Control Applications. Milwaukee: ASQ Quality Press. 2001.

20. Morris ZS, Wooding S, Grant J. The answer is 17 years, what is the question: understanding time lags in translational research. J R Soc Med. 2011;104:510-520.

21. Brownson RC, Kreuter MW, Arrington BA, True WR. Translating Scientific Discoveries Into Public Health Action: How Can Schools Of Public Health Move Us Forward? Public Health Rep. 2006;121(1):97-103.

22. Bero LA, Grilli R, Grimshaw JM, Harvey E, Oxman AD, Thomson MA. Closing the gap between research and practice: an overview of systematic reviews of interventions to promote the implementation of research findings. The Cochrane Effective Practice and Organization of Care Review Group. BMJ. 1998;317(7156):465-468.

23. Greenhalgh T, Robert G, Macfarlane F, Bate P, Kyriakidou O. Diffusion of innovations in service organizations: systematic review and recommendations. Milbank $Q$. 2004;82(4):581-629.

24. Agency for Healthcare Research and Quality. Research Protocol-Jul. 31, 2012: Communication and Dissemination Strategies To Facilitate the Use of Health and Health Care Evidence. Available at:

https://effectivehealthcare.ahrq.gov/ehc/products/433/1208/CommunicationDisseminatio n_ResearchProtocol_20120731.pdf2012.

25. Grimshaw JM, Eccles MP, Lavis JN, Hill SJ, Squires JE. Knowledge translation of research findings. Implement Sci. 2012;7:50.

26. Bodison SC, Sankaré I, Anaya H, et al. Engaging the Community in the Dissemination, Implementation, and Improvement of Health-Related Research. Clin. Transl. Sci. 2015;8(6):814-819.

27. Slatore CG, Baumann C, Pappas M, Humphrey LL. Smoking behaviors among patients receiving computed tomography for lung cancer screening. Systematic review in support of the U.S. preventive services task force. Ann Am Thorac Soc. 2014;11(4):619-627.

28. Pineiro B, Simmons VN, Palmer AM, Correa JB, Brandon TH. Smoking cessation interventions within the context of Low-Dose Computed Tomography lung cancer screening: A systematic review. Lung Cancer. 2016;98:91-98.

29. US Census Bureau. State and County QuickFacts. 2015 estimates. Available at: http://www.census.gov/quickfacts/table/PST045215/00.

30. Brian Kiser for the Commonwealth Office of Broadband Outreach and Development. Broadband Speed and Access in Kentucky. National Association of Regional Councils: Kentucky Digital Summit 2014; 10-14-2014.

31. Institute of Medicine (US) Committee on Health and Behavior: Research P, and Policy. Health and Behavior. 7, Evaluating and Disseminating Intervention Research. Health and Behavior: The Interplay of Biological, Behavioral, and Societal Influences. Available at: http://www.ncbi.nlm.nih.gov/books/NBK43735/2001.

32. Carter-Harris L, Ceppa DP, Hanna N, Rawl SM. Lung cancer screening: what do longterm smokers know and believe? Health Expect. 2015. doi:10.1111/hex.12433

33. Yabroff KR, Lamont EB, Mariotto A, et al. Cost of Care for Elderly Cancer Patients in the United States. J. Natl. Cancer Inst. 2008;100(9):630-641.

34. Clegg L, Reichman M, Miller B, et al. Impact of socioeconomic status on cancer incidence and stage at diagnosis: selected findings from the surveillance, epidemiology, 
and end results: National Longitudinal Mortality Study. Cancer Causes Control. 2009;20(4):417-435.

35. Forrest LF, Adams J, Wareham H, Rubin G, White M. Socioeconomic Inequalities in Lung Cancer Treatment: Systematic Review and Meta-Analysis. PLoS Med. 2013;10(2):e1001376. 
Table 1. Health Statistics of the Terminate Lung Cancer Focus Group Regions

\begin{tabular}{|c|c|c|c|c|c|}
\hline & $\begin{array}{l}\text { Pikeville } \\
\text { Region* }\end{array}$ & $\begin{array}{l}\text { Hazard } \\
\text { Region* }\end{array}$ & $\begin{array}{l}\text { Morehead } \\
\text { Region* }\end{array}$ & Kentucky & $\mathbf{U S}$ \\
\hline Estimated Total Population ${ }^{\dagger, \ddagger}$ & 138,374 & 123,067 & 118,309 & $4,395,295$ & $318,857,056$ \\
\hline $\begin{array}{l}\text { High School Graduation } \\
\text { (adults age } 25 \text { or older) }^{\S, \|}\end{array}$ & $69.3 \%$ & $63.4 \%$ & $70.4 \%$ & $82.0 \%$ & $81.0 \%$ \\
\hline Median household income & $\$ 28,111$ & $\$ 25,322$ & $\$ 26,210$ & $\$ 41,576$ & $\$ 53,046$ \\
\hline Prevalence of Smoking ${ }^{\#, * *}$ & $33.3 \%$ & $33.4 \%$ & $30.0 \%$ & $28.0 \%$ & $17.8 \%$ \\
\hline $\begin{array}{l}\text { Premature death (Number of } \\
\text { years of potential life lost } \\
\text { prior to age } 75 \text { per } 100,000 \\
\text { population) }\end{array}$ & 18,282 & 16,569 & 12,093 & 7,562 & 6,976 \\
\hline
\end{tabular}

Cancer Deaths (age-adjusted per 100,000 population) $)^{\S \S, \sharp \dagger}$

$\begin{array}{llllll}\text { All cancers } & 240.8 & 251.9 & 224.4 & 212.0 & 171.2 \\ \text { Lung and Bronchus } & 95.5 & 97.0 & 77.8 & 75.0 & 47.2\end{array}$

*Pikeville Region includes Pike, Letcher, Floyd, Martin counties; Hazard Region includes Perry, Knott, Harlan, Leslie, Breathitt, Clay, Owsley counties; Morehead Region includes Rowan, Fleming, Lewis, Carter, Elliott, Morgan, Menifee, Bath counties.

Data sources: †Population Division, U.S. Census Bureau, ${ }^{\ddagger} \mathrm{http} / /$ quickfacts.census.gov, $\S$, II American Community Survey, U.S. Census Bureau, "National Center for Education Statistics, \#Behavioral Risk Factor Surveillance System, ${ }^{* *}$ Centers for Disease Control and Prevention: fast facts, ${ }^{\dagger}$ Kentucky State Data Center - Vital Statistics, ${ }^{\dagger}$ National Cancer Institute: Surveillance,

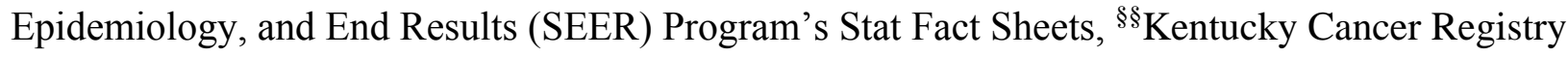


Table 2. Exposure and Behavior Survey Results

\section{General Exposure}

Have you seen or heard any ads, messages, or postcards about lung cancer screening?

\begin{tabular}{lll} 
& Yes & \\
Respondents & Response & $\%$ Yes \\
\hline 145 & 73 & 50.3
\end{tabular}

If Yes, Source: ${ }^{a}$

television

\begin{tabular}{lll}
$f$ & & $\%$ \\
\cline { 1 - 1 } 33 & & 45.2 \\
18 & & 24.7 \\
31 & & 42.5 \\
4 & & 5.5 \\
5 & & 6.9 \\
8 & & 10.95
\end{tabular}

Radio

10.95

If Yes, Did it make you?: ${ }^{a}$

Think about quitting smoking

\begin{tabular}{|c|c|}
\hline$f$ & $\%$ \\
\hline 41 & 28 \\
\hline 4 & 2.8 \\
\hline 7 & 4.8 \\
\hline 23 & 15.9 \\
\hline 13 & 9 \\
\hline 5 & 3.4 \\
\hline 5 & 3.4 \\
\hline 0 & 0 \\
\hline 2 & 1.4 \\
\hline
\end{tabular}

Look for more information about quitting smoking

Develop a plan to quit smoking

Talk to a doctor about quit smoking

Actually quit smoking

Think about getting a low-dose CT scan for lung cancer screening

Actually get a low-dose CT scan for lung cancer screening

Talk to family or other amount lung cancer screening

Look for more information about screening

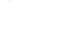

\footnotetext{
${ }^{a}$ Presented as frequency $(f)$ of response, as more than one response could be provided for each question.
} 
Figure 1. Targeted population regions. Morehead, Hazard regions served as Intervention Regions. Pikeville served as a Control Region.

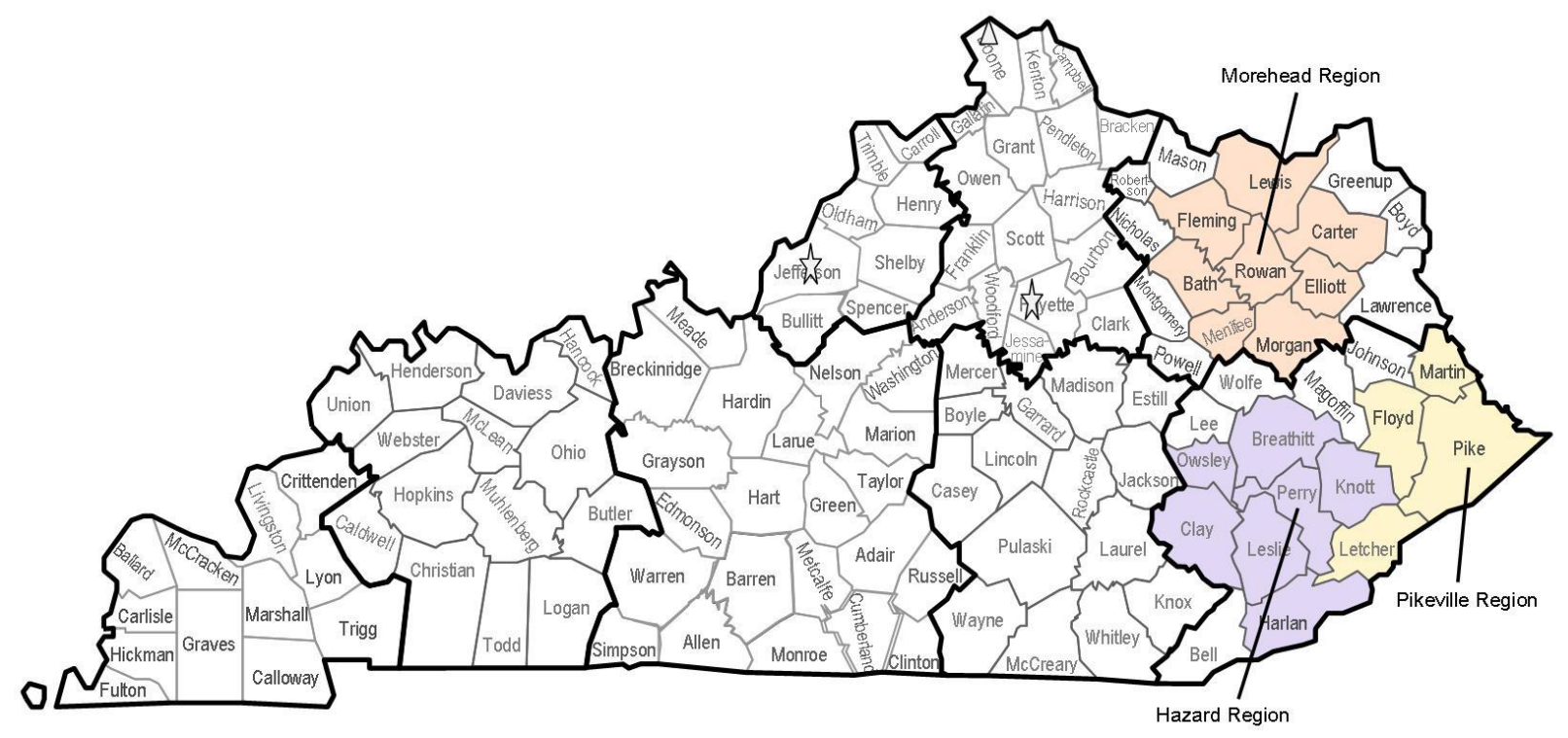


Figure 2. Campaign messaging and images

\section{Radio ad content:}

"Support comes from the U-K College of Medicine and the Department of Family and Community Medicine, dedicated to reducing lung cancer deaths in Eastern Kentucky through the Terminate Lung Cancer Project. Adults ages fifty-five and older with a history of smoking or who have quit smoking less than 15 years ago are encouraged to talk to their doctor or health care provider about whether a Low-Dose C-T Scan of the chest is right for them. You can learn more online at: t-e-r-m-i-n-a-t-e-l-un-g-c-a-n-c-e-r dot o-r-g."

\section{$\underline{\text { Postcard Images: }}$}
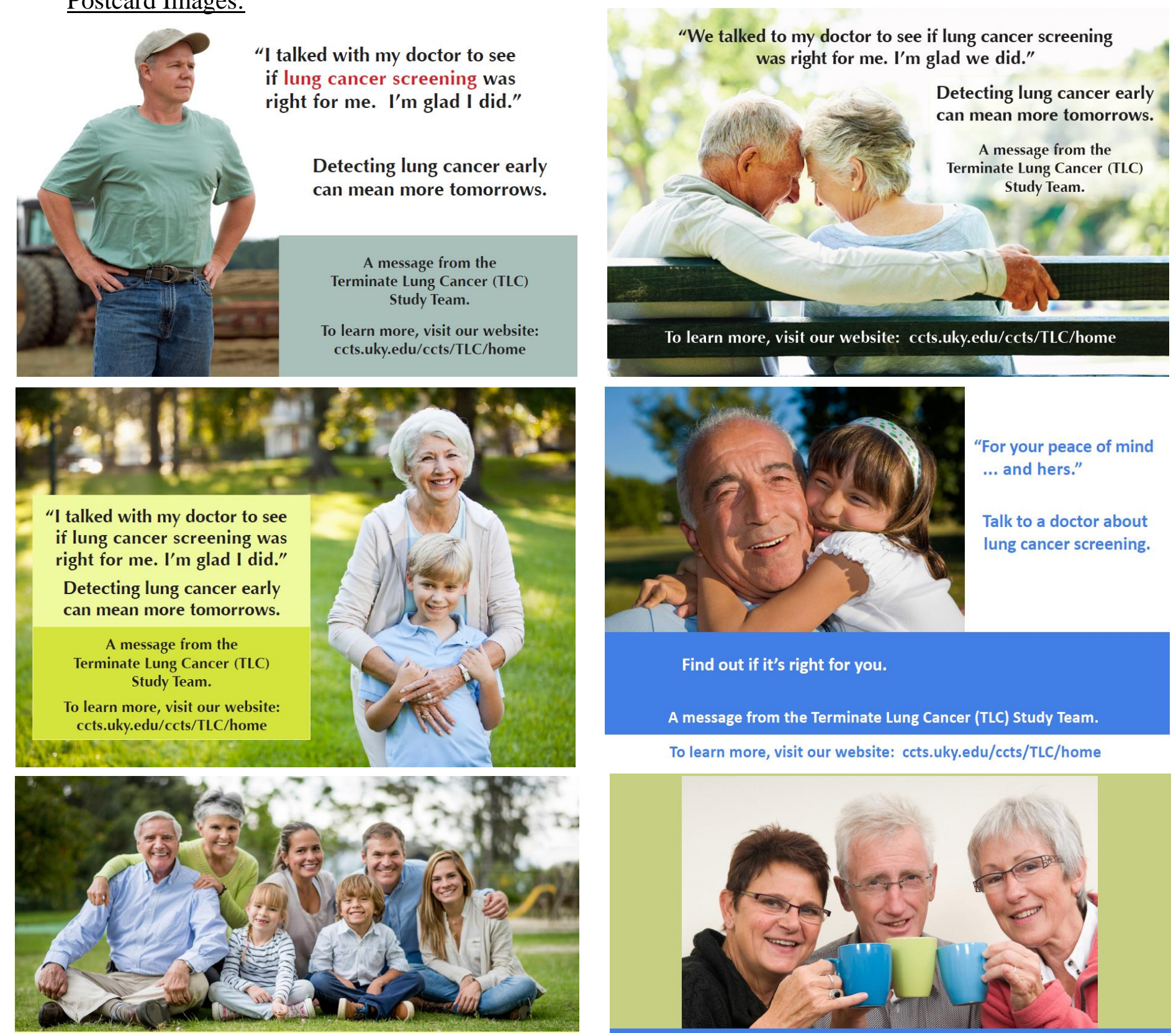

"For your peace of mind ... and theirs."

Talk to a doctor about lung cancer screening. Find out if it's right for you.

A message from the Terminate Lung Cancer (TLC) Study Team. To learn more, visit our website: ccts.uky.edu/ccts/TLC/home

To learn more, visit our website: ccts.uky.edu/ccts/TLC/home

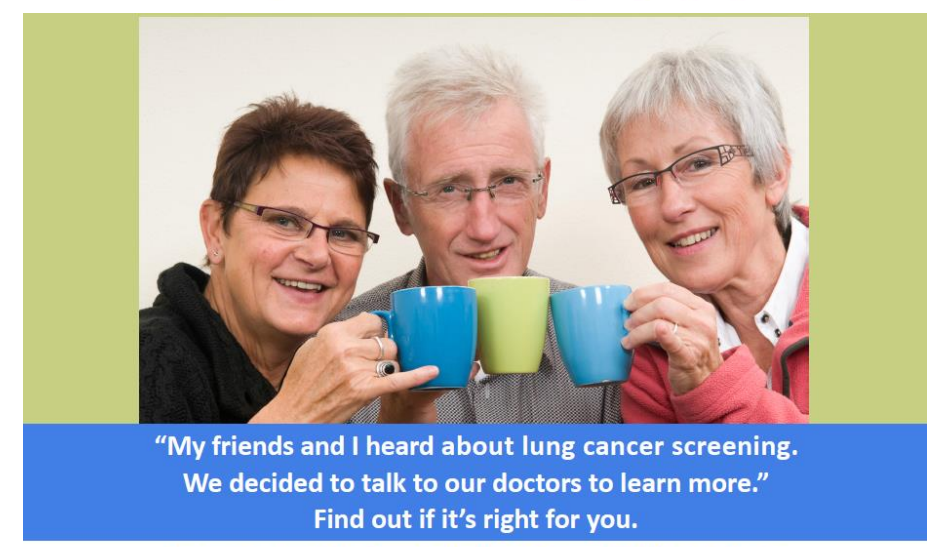

A message from the Terminate Lung Cancer (TLC) Study Team. To learn more, visit our website: ccts.uky.edu/ccts/TLC/home 
Figure 3a. C-Control Charts by Region: Intervention Regions
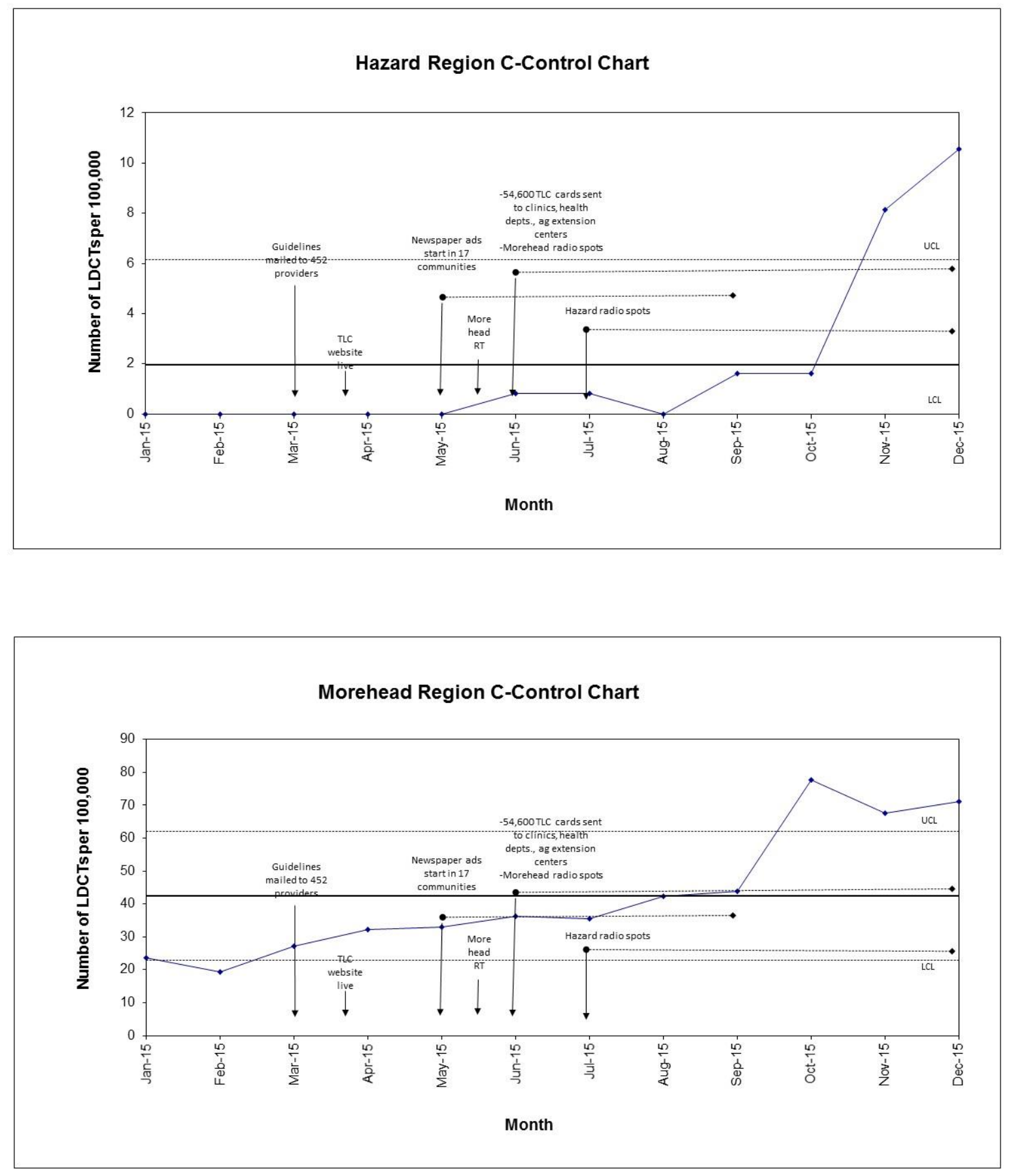
Figure 3b. C-Control Charts by Region: Control Region

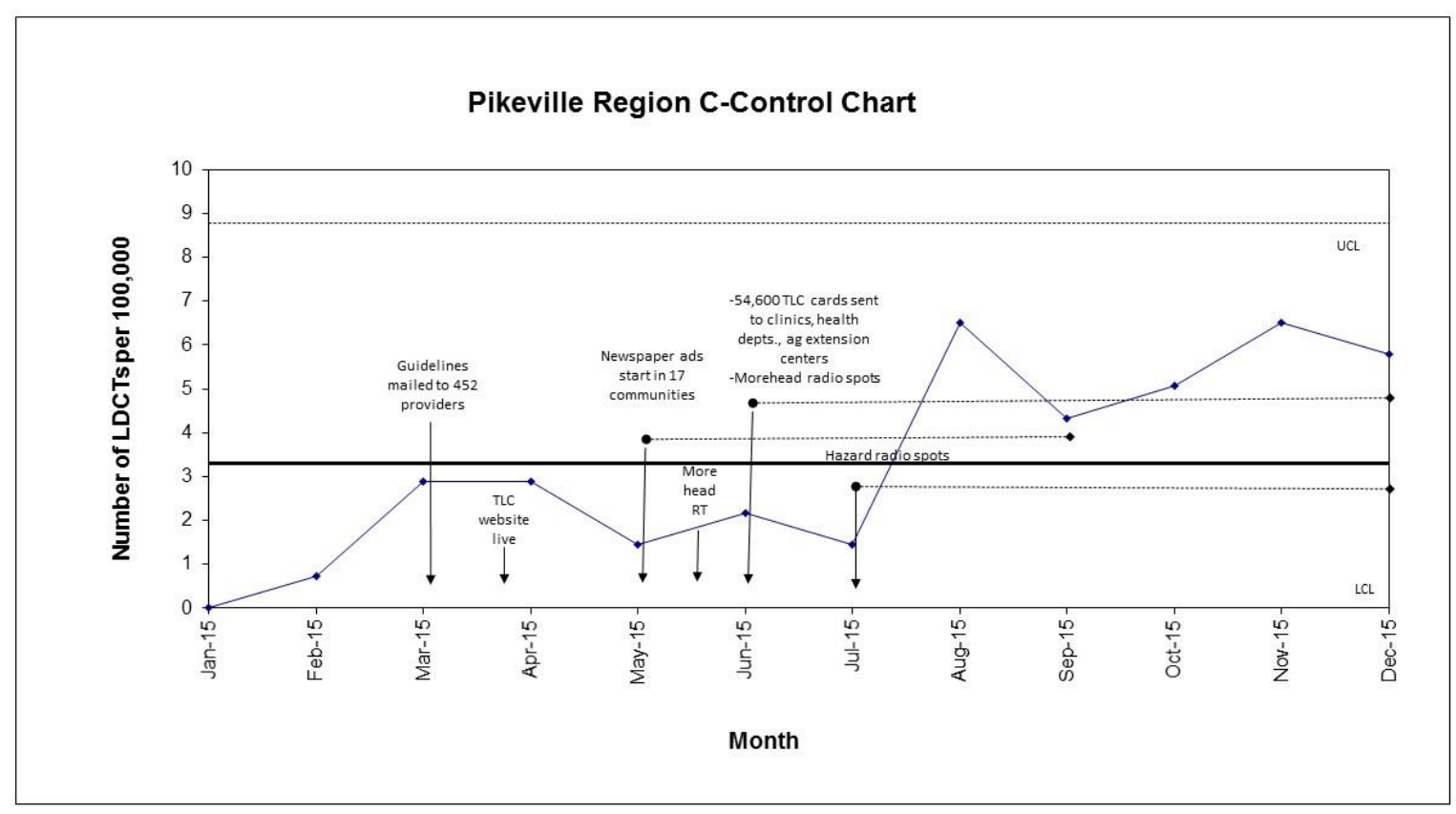

